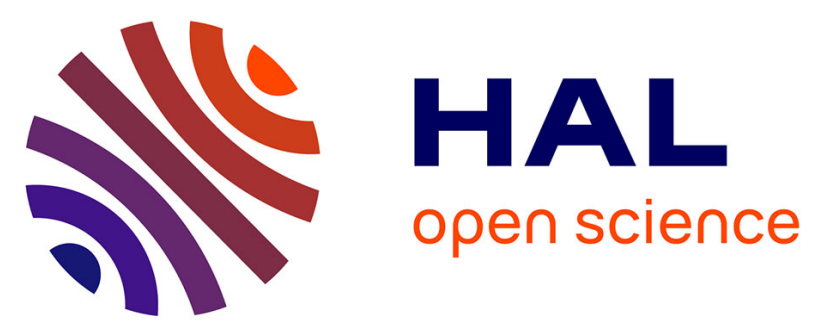

\title{
Early Intermittent Interturn Fault Detection and Localization for a Permanent Magnet Synchronous Motor of Electrical Vehicles Using Wavelet Transform
} Najla Haje Obeid, Alexandre Battiston, Thierry Boileau, Babak Nahid-Mobarakeh

\section{To cite this version:}

Najla Haje Obeid, Alexandre Battiston, Thierry Boileau, Babak Nahid-Mobarakeh. Early Intermittent Interturn Fault Detection and Localization for a Permanent Magnet Synchronous Motor of Electrical Vehicles Using Wavelet Transform. IEEE Transactions on Transportation Electrification, 2017, 3 (3), pp.694 - 702. 10.1109/TTE.2017.2743419 . hal-01739985

\section{HAL Id: hal-01739985 \\ https://hal-ifp.archives-ouvertes.fr/hal-01739985}

Submitted on 26 Jul 2018

HAL is a multi-disciplinary open access archive for the deposit and dissemination of scientific research documents, whether they are published or not. The documents may come from teaching and research institutions in France or abroad, or from public or private research centers.
L'archive ouverte pluridisciplinaire HAL, est destinée au dépôt et à la diffusion de documents scientifiques de niveau recherche, publiés ou non, émanant des établissements d'enseignement et de recherche français ou étrangers, des laboratoires publics ou privés. 


\section{Early intermittent inter-turn fault detection and localization for a permanent magnet synchronous motor of electrical vehicles using wavelet transform}

Najla Haje Obeid, Alexandre Battiston, Member, IEEE, Thierry Boileau and Babak Nahid-Mobarakeh, Senior Member, IEEE

\begin{abstract}
In order to improve hybrid and electrical vehicles functional safety and to avoid sudden failures, it is important to develop reliable and robust onboard diagnostics (OBD). This paper discusses the stator incipient fault diagnosis and monitoring of a permanent magnet synchronous motor for hybrid and electrical vehicles. Incipient stator fault appears as intermittent inter-turn faults. Studying this phenomenon had shown that it generates specific distortions in the statoric currents as well as in the reference voltages. The fault monitoring method is based on the identification of these specific distortions and on the localization of the phase containing the defected turns. The theoretical and the experimental results show the effectiveness of the method.

Keywords-adapted wavelet, fault detection, fault localization, incipient fault, intermittent fault, inter-turn fault, pattern detection, prevention.
\end{abstract}

\section{INTRODUCTION}

The monitoring strategies requirements associated to electrical machines in automotive applications are more and more oriented to identify defects from their first symptoms. The functional safety standard (ISO 26262) was developed by the automotive community [1]. For the different development process phases, this standard defines the functional safety requirements and life-cycle management. According to [2], an effective way to guarantee the hybrid or electrical vehicles functional safety is to develop onboard diagnostics (OBD) that are in compliance with the functional safety standards. Early detection is important to avoid sudden failure and to improve machines availability [2]. In addition, failure presence influences negatively on the machine performance. The last one being an important parameter in automotive application, incipient fault detection reveals important.

Permanent magnet synchronous motors (PMSM) are widely used in hybrid and electric vehicles because of their high-efficiency, their high-power density and their compact design $[3,4]$. The insulation breakdown between two turns in the stator winding consist a critical electrical machine fault [5]. Many studies have been developed in order to detect this type of fault [6]. So far, the studies were restricted to an advanced fault case modeled by a permanent inter-turn short circuit [7-12]. The developed identification methods are mostly based on frequency analysis [7-12]. It has been proven that the permanent inter-turn fault presence affect the third harmonic component in the $(\mathrm{a}, \mathrm{b}, \mathrm{c})$ frame and the second component in the $(\mathrm{d}, \mathrm{q})$ frame [12].

To improve the functional safety, early fault detection is needed. To perform this, it is necessary to have information about incipient fault. Our previous works had led us to define the intermittent inter-turn fault as an earlier stage than the permanent inter-turn short circuit [13]. In fact, stator winding turns are subject to electromagnetic field which generates the electromagnetic forces [14]. These forces cause stator turns mechanical vibrations, notably, at the end winding region. The vibrating phenomenon degrades the insulation material and accelerates its aging [15]. Thus the probability of failure presence increases. Incipient winding failure appears as intermittent inter-turn short circuits notably between the stator end winding turns [13]-[16].

In previous papers [13]-[17], we have presented the intermittent inter-turn fault model. After studying the fault presence consequences [17] and after testing the literature permanent inter-turn fault detection methods, we have realized that intermittent fault needs its proper identification method. Paper [13] was dedicated to the intermittent fault detection. It was restricted to the fault identification and didn't treat the localization of the phase containing the defected turns. This paper is dedicated to the localization of the intermittent interturn fault and is written to present a global detection method. It begins with a brief review on the intermittent fault and on its identification method using adapted wavelet. After it continues with the faulty phase localization using the phase to phase voltages. To better understand the localization method, detailed analytical equations are provided. Finally, experimental results are provided to show the effectiveness of the global method.

\section{REVIEW ON THE INTERMITTENT FAULT}

As mentioned in the introduction, the intermittent fault is caused by the turns vibrations. In the context of an incipient fault, if we consider two vibrating turns lightly defected, the firsts short circuits occur between them when they are the closest and disappear as soon as they move off. The vibrating turns are the closest when the electromagnetic forces are maximum. According to Laplace forces equation, the electromagnetic efforts are proportional to the square of the current passing through the winding. Thus, for a stator winding phase fed by an alternative current, the possibility of incipient intermittent fault occurrence is higher when the current is near its peak value. For the rest of the paper, the equivalent model of the incipient studied fault is an intermittent inter-turn short circuit occurring from time to time near the current peaks [13].

In Fig. 1 is presented the equivalent PMSM stator winding with an intermittent fault between the turns of the phase " $a$ ". A variable resistance $R_{f}$ is used to model the intermittent short circuit. In presence of inter-turn short 
circuit, $R_{f}$ takes a low value (noted $R_{f . s c . o n}$ ) allowing by that the current flow between the defective turns [18]. The $R_{f . s c o n}$ value depends on the insulation damage degree. In absence of short circuit, $R_{f}$ takes a high value ( noted $R_{f . s c . o f f}$ ) stopping by that the current flow between them. The resulting PMSM equation system under intermittent fault conditions on the phase " $a$ " is given by the equation (1) [13]-[17].

$$
\begin{aligned}
& {\left[\begin{array}{c}
v_{a} \\
v_{b} \\
v_{c} \\
0
\end{array}\right]=\left[\begin{array}{cccc}
R_{s} & 0 & 0 & -R_{a 1} \\
0 & R_{s} & 0 & 0 \\
0 & 0 & R_{s} & 0 \\
-R_{a 1} & 0 & 0 & R_{a 1}+R_{f}
\end{array}\right]\left[\begin{array}{c}
i_{a} \\
i_{b} \\
i_{c} \\
i_{f}
\end{array}\right]+\left[\begin{array}{c}
e_{a} \\
e_{b} \\
e_{c} \\
-e_{a 1}
\end{array}\right]} \\
& +\left[\begin{array}{cccc}
L_{s} & 0 & 0 & -l_{a 1}-M_{a 1 a 2} \\
0 & L_{s} & 0 & -M_{b c a 1} \\
0 & 0 & L_{s} & -M_{b c a 1} \\
-l_{a 1}-M_{a 1 a 2}+M_{b c a 1} & 0 & 0 & l_{a 1}
\end{array}\right] \frac{d}{d t}\left[\begin{array}{c}
i_{a} \\
i_{b} \\
i_{c} \\
i_{f}
\end{array}\right](1)
\end{aligned}
$$

With $v_{a}, v_{b}, v_{c}$ the statoric phase voltages; $i_{a}, i_{b}, i_{c}$ the statoric currents; $e_{a}, e_{b}, e_{c}$ the electromotive forces; $R_{s}$ the stator one phase resistance; $L_{s}$ the stator one phase inductance; $i_{f}$ the short circuit current; $e_{a 1}$ the short circuited turns electromotive force; $R_{a 1}$ the short circuited turns resistance; $l_{a 1}$ the short circuited turns inductance; $M_{a 1 a 2}$ the mutual inductance between the short circuited turns and the rest of the phase " $a$ " and finally $M_{b c a 1}$ the mutual inductance between the short circuited turns and the phases " $b$ " or " $c$ ".

Terms related to the intermittent fault and referenced with the index " $a_{l}$ " depend on two parameters: the ratio of the short circuited turns to the total number of turns per phase $(\mu)$ and the value of $R_{f . s c . o n}$. These two parameters modifies the stator currents as well as the voltages. For a given machine, they are related to the fault to detect which make them unknown. Later on, several values of $\mu$ and $R_{\text {f.scon }}$ will be considered to show the method effectiveness. In electrical vehicles, PMSM field oriented control is most often used. For that reason, in this paper, the PMSM is current controlled using a pulse width modulation voltage inverter as shown in Fig. 2. The PMSM characteristics are given in Table 1.

\section{FAULT DETECTION AND LOCALIZATION}

The intermittent fault identification process is divided into two steps. The first one is the intermittent fault identification using an adapted wavelet transform. In case of intermittent fault detection, the next step consists in comparing the phase to phase voltages in order to identify the defected phase.

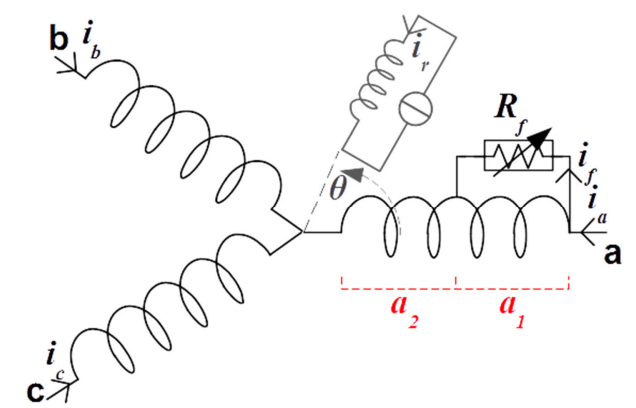

Fig. 1 : PMSM stator winding with an intermittent fault

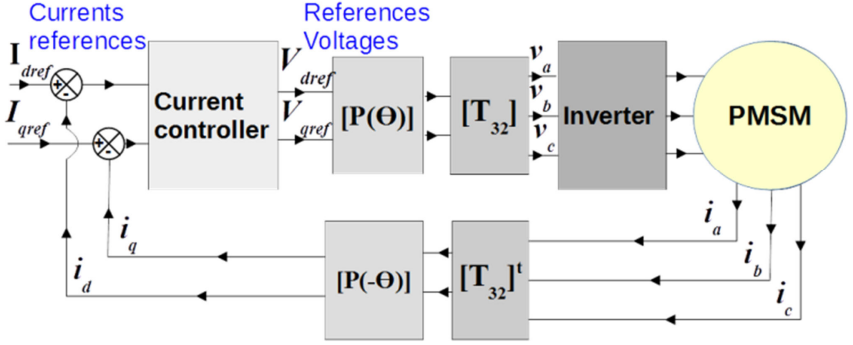

Fig. 2 : Block diagram of the PMSM control system

Table 1 : Characteristics of the PMSM used in this paper

\begin{tabular}{|l|l|l|l|}
\hline Rated Power & $1000 \mathrm{~W}$ & Poles number & 8 \\
\hline Rated speed & $1500 \mathrm{rpm}$ & Stator inductance & $1.8 \mathrm{mH}$ \\
\hline DC voltage bus & $300 \mathrm{~V}$ & Stator resistance & $0.26 \mathrm{Ohms}$ \\
\hline Rated current & $3 \mathrm{~A}$ & Magnetic flux & $0.119 \mathrm{~Wb}$ \\
\hline
\end{tabular}

A. Intermittent fault detection using adapted wavelet transform

In previous work [13]-[17] we have demonstrated that the intermittent fault generates defined distortions in the statoric currents and voltages. Our several tests had proven that these distortions keep always the same shape [17]. They are proper to the intermittent fault, and can be defined as its signatures. For a given PMSM, their scale differs according to the operating points, the regulation and the intermittent fault parameters [17]. Besides that, an incipient fault is not periodic, it occurs from time to time near the current peaks.

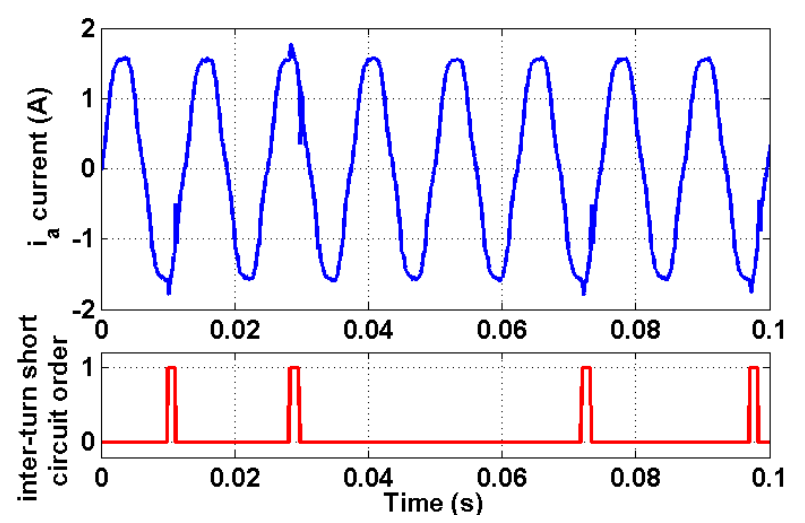

Fig. 3 : Example of $i_{a}$ current accompigned by the inter-turn short circuit state

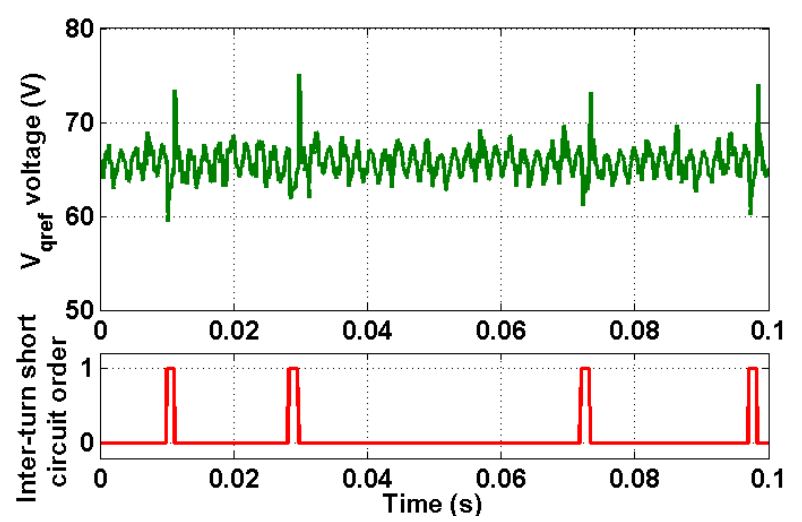

Fig. 4 : Example of $V_{\text {qref }}$ voltage accompigned by the inter-turn short circuit state 


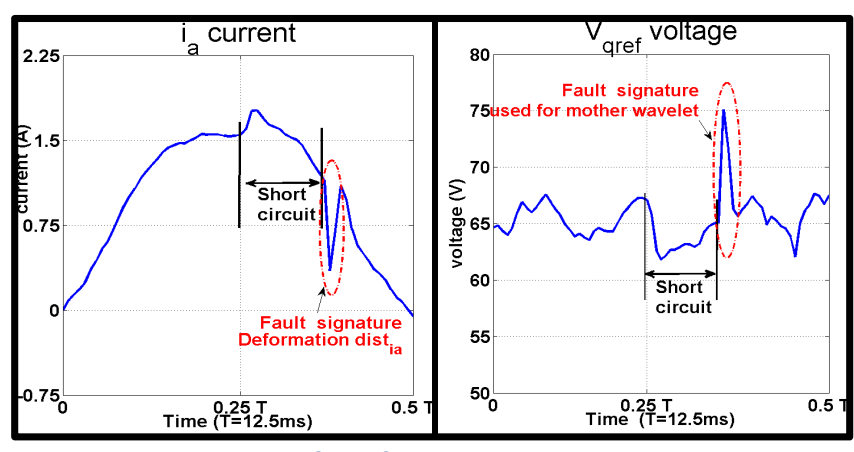

Fig. 5 : Example of the fault signatures in the $i_{a}$ and $V_{q r e f}$

An example of the distortions caused by the intermittent fault is given in Fig. 3 and 4. The example corresponds to: $I_{\text {qref }}=2 \mathrm{~A}, \Omega=600 \mathrm{rpm}, k_{p}=15, \mu=6.25 \%$ and $R_{f . s c . o n}=0$; with $\Omega$ the rotor speed and $k_{p}$ the PI controller proportional gain. Fig. 3 shows $i_{a}$ current under fault conditions on the phase " $a$ " while Fig. 4 shows $V_{\text {qref }}$ voltage. In Fig. 5, we present an example of the fault signatures in both $i_{a}$ and $V_{\text {qref }}$. The fault signatures are the deformation generated at the end of the intermittent short-circuit.

Based on the above facts, identifying the intermittent fault can be performed using a pattern detection method. The pattern to identify is the fault signature (Fig. 5) and the identification should be feasible independently of its scale. If the Fault Signature $(F S)$ scale was known, a convolution product between a measured signal (for example $V_{\text {qref }}$ ) and the FS pattern in this signal would be enough. The fault identification will be seen as a correlation between the fault signature and the pattern. Or as the FS scale is related to the fault to detect, it is an unknown parameter. That is why we have opted for an adapted wavelet transform. In addition, the wavelet transform is not only a time-frequency robust method [19] but it is also sensitive to small variation in a signal [20]. To ensure good pattern detection, good pattern representation is needed. The best basis to represent the fault signature is an adapted wavelet [21-26].

The aim of this paper is to present a detection method able to identify the faulty winding phase. The intermittent fault detection using the adapted wavelet had been developed in previous paper, therefore we will limit to a brief review on the main points [13]:

1. The best candidate for intermittent fault detection is the reference voltage $V_{\text {qref }}$.

2. Adapted wavelet transform is applied to $V_{\text {qref }}$ after removing its mean value $\left(\left\langle V_{\text {qref }}\right\rangle\right)$.

3. A comparison between the wavelet transform (WT) positive parts max value and the detection threshold determined for a healthy machine is needed for fault identification. If the max is below the threshold, there is no intermittent fault detection. If the max is higher than the threshold, an intermittent fault is possible. To detect it, we proceed to step 4.

4. Calculus of the "Signal To Noise Ratio Improvement" (STNRI) in the signal after wavelet transform. It is the intermittent fault indicator. A STRNI higher than $100 \%$ signifies that the pattern detection of the fault signature has occurred.
An example of the intermittent fault identification method is given in Fig. 6, 7 and 8. The example corresponds to the same operating point as in the previous figures. In Fig. 6 is presented the WT under fault conditions while in Fig. 7 is presented the $W T$ under healthy ones. Comparing both figures shows that the WT max value in presence of fault is higher. The detection threshold is defined using the WT max value under healthy conditions. In Fig. 7, it is equal to 2.50 .

In the follow, we proceed to the STNRI calculation. To begin, in the wavelet transform, each dilatation coefficient $(\delta)$ generates a corresponding signal $(W T(\delta))$. To calculate the $S T N R I$, we select the $W T(\delta)$ containing the $\max$ values $\left(W T\left(\delta_{M A}\right)\right)$. In the example of Fig. 6, it corresponds to a dilatation $\delta_{M A}$ equal to 0.0015 . Then we compare this signal to the original $V_{\text {qref }}$ without its mean value $\left(V_{\text {qref }}{ }^{-}\left\langle V_{\text {qref }}\right\rangle\right)$. An example of these two signals is given in Fig. 8.

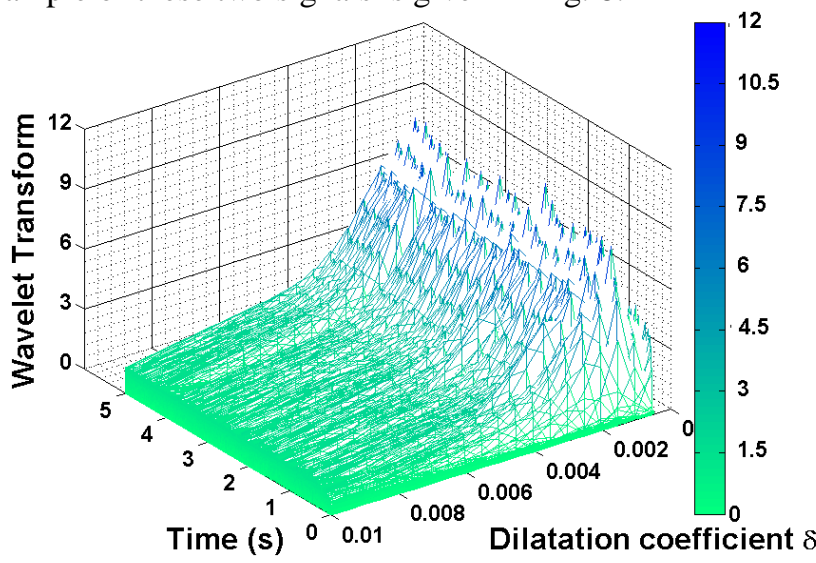

Fig. 6 : 3D wavelet transform graph under fault conditions

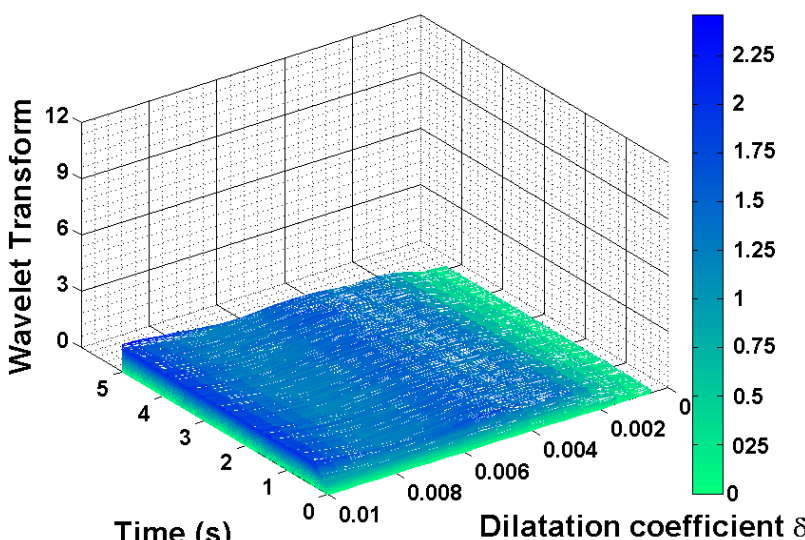

Fig. 7 : 3D wavelet transform graph under healthy conditions

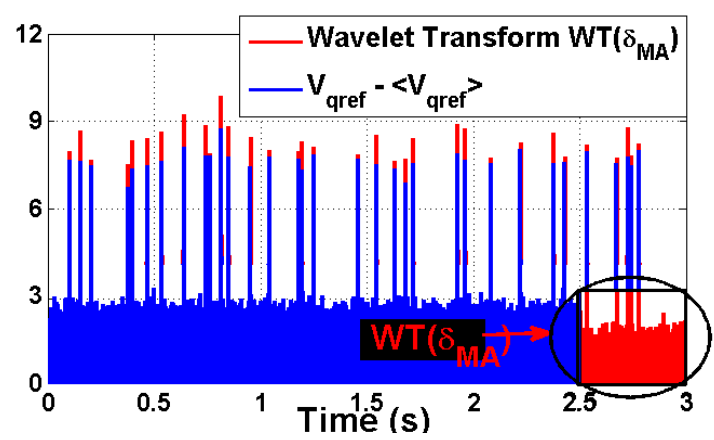

Fig. 8 : Comparision between $W T\left(\delta_{M A}\right)$ and $\left(V_{\text {qref }}=\left\langle V_{\text {qref }}\right\rangle\right)$ 
The STNRI is defined by:

$$
\text { STNRI }=\frac{\text { Signal To Noise Ratio }(\text { WT }(\delta M A))}{\text { Signal To Noise Ratio }(\text { Vqref }-<\text { Vqref }>)}
$$

For the example in Fig. 8, the STNRI is equal to $147 \%$. A value higher than $100 \%$ indicates that the wavelet basis corresponding to $\delta_{M A}$ has correlated with the fault signature. The intermittent fault signature not only has been detected, but also the signal to noise ratio has been improved by $47 \%$.

B. Intermittent fault localization using phase to phase voltages

The intermittent fault generates a disequilibrium in the stator winding phases. The faulty phase identification is based on the detection of this imbalance. The localization is based on a comparison between the phase to phase voltages.

\section{1) Analytical expressions}

To better understand the localization method, analytical study will be detailed. In equation (3), we rewrite the PMSM equation system (1) under fault conditions on the phase " $a$ " in function of the three phase to phase voltages. This system will be used for the statoric currents calculus.

$$
\begin{gathered}
{\left[\begin{array}{c}
v_{a}-v_{b} \\
v_{b}-v_{c} \\
v_{c}-v_{a}
\end{array}\right]=\left[\begin{array}{cccc}
R_{s} & 0 & 0 & -R_{a 1} \\
0 & R_{s} & 0 & 0 \\
0 & 0 & R_{s} & R_{a 1}
\end{array}\right]\left[\begin{array}{c}
i_{a}-i_{b} \\
i_{b}-i_{c} \\
i_{c}-i_{a} \\
i_{f}
\end{array}\right]+\left[\begin{array}{c}
e_{a}-e_{b} \\
e_{b}-e_{c} \\
e_{c}-e_{a}
\end{array}\right]} \\
+\left[\begin{array}{cccc}
L_{s} & 0 & 0 & -l_{a 1}-M_{a 1 a 2}+M_{b c a 1} \\
0 & L_{s} & 0 & 0 \\
0 & 0 & L_{s} & l_{a 1}+M_{a 1 a 2}-M_{b c a 1}
\end{array}\right] \frac{d}{d t}\left[\begin{array}{c}
i_{a}-i_{b} \\
i_{b}-i_{c} \\
i_{c}-i_{a} \\
i_{f}
\end{array}\right]
\end{gathered}
$$

As mentioned in the section II, the PMSM is current controlled in the $(d, q)$ frame using a PI controller as shown in Fig. 2. Current is collected in the $(a, b, c)$ frame then it is transferred to the $(d, q)$ frame using Park transform $\left(P(-\theta) T_{32}^{t}\right)$ as in equation (4). $T_{32}$ and $P(\theta)$ are the Concordia and the rotation matrix.

$$
i_{d q}=P(-\theta) T_{32}^{t} i_{a b c}
$$

The reference voltages at the output of the current controller are given in equation (5). $k_{p}$ and $k_{i}$ are the proportional and the integral PI gains.

$$
\left\{\begin{array}{l}
V_{\text {dref }}=k_{p}\left(I_{\text {dref }}-i_{d}\right)+k_{i} \int\left(I_{\text {dref }}-i_{d}\right) d t \\
V_{\text {qref }}=k_{p}\left(I_{\text {qref }}-i_{q}\right)+k_{i} \int\left(I_{\text {qref }}-i_{q}\right) d t
\end{array}\right.
$$

The control system is discrete with a sampling period $T_{e}$. Currents collected at a time $t_{n}$ (equation (6)), allow determining the inverter input voltages at a time $t_{n+1}$.

$$
t_{n}=n T_{e} ; \quad n \in \mathbb{N}
$$

The three phase to phase voltages applied as pulse wave reference at the inverter input are obtained from $\left(V_{\text {dref }}, V_{\text {qref }}\right)$ after a $(d, q)-(a, b, c)$ transform. This transition is realized using the equation (7). The three phase to phase voltages are given in equation (8), (9) and (10).

$$
v_{a b c}=T_{32} P(\theta) V_{\text {dqref }}
$$

$$
\begin{aligned}
& v_{a b(n+1) T_{e}}=\left(v_{a}-v_{b}\right)_{(n+1) T_{e}}=\sqrt{2}\left(\sin \left(\theta_{n T_{e}}-\frac{4 \pi}{3}\right) I_{d r e f}+\right. \\
& \left.\cos \left(\theta_{n T_{e}}-\frac{4 \pi}{3}\right) I_{q r e f}\right)\left(k_{p}+k_{i} n T_{e}\right)-\left(k_{p}+T_{e} k_{i}\right)\left(i_{a\left(n T_{e}\right)}-\right. \\
& \left.i_{b\left(n T_{e}\right)}\right)+k_{i} T_{e} \sum_{j=0}^{n-1}\left(-\cos \left(\theta_{n T_{e}}-\theta_{j T_{e}}\right)\left(i_{a(j T e)}-i_{b\left(j T_{e}\right)}\right)+\right. \\
& \left(\sqrt{3} \sin \left(\theta_{n T_{e}}-\theta_{j T_{e}}\right)\left(i_{a(j T e)}+i_{b\left(j T_{e}\right)}\right)\right) \\
& v_{b c(n+1) T_{e}}=\left(v_{b}-v_{c}\right)_{(n+1) T_{e}}=\sqrt{2}\left(\sin \left(\theta_{n T_{e}}\right) I_{d r e f}+\right. \\
& \left.\cos \left(\theta_{n T_{e}}\right) I_{q r e f}\right)\left(k_{p}+k_{i} n T_{e}\right)-\left(k_{p}+T_{e} k_{i}\right)\left(i_{b\left(n T_{e}\right)}-\right. \\
& \left.i_{c\left(n T_{e}\right)}\right)+k_{i} T_{e} \sum_{j=0}^{n-1}\left(-\cos \left(\theta_{n T_{e}}-\theta_{j T_{e}}\right)\left(i_{b(j T e)}-i_{c\left(j T_{e}\right)}\right)+\right. \\
& \left.\left(\sqrt{3} \sin \left(\theta_{n T_{e}}-\theta_{j T_{e}}\right)\left(i_{b(j T e)}+i_{c\left(j T_{e}\right)}\right)\right)\right) \\
& v_{c a(n+1) T_{e}}=\left(v_{c}-v_{a}\right)(n+1) T_{e}=\sqrt{2}\left(\sin \left(\theta_{n T_{e}}-\frac{2 \pi}{3}\right) I_{d r e f}+\right. \\
& \left.\cos \left(\theta_{n T_{e}}-\frac{2 \pi}{3}\right) I_{q r e f}\right)\left(k_{p}+k_{i} n T_{e}\right)-\left(k_{p}+T_{e} k_{i}\right)\left(i_{c\left(n T_{e}\right)}-\right. \\
& \left.i_{a\left(n T_{e}\right)}\right)+k_{i} T_{e} \sum_{j=0}^{n-1}\left(-\cos \left(\theta_{n T_{e}}-\theta_{j T_{e}}\right)\left(i_{c(j T e)}-i_{a\left(j T_{e}\right)}\right)+\right. \\
& \left(\sqrt{3} \sin \left(\theta_{n T_{e}}-\theta_{j T_{e}}\right)\left(i_{c(j T e)}+i_{a\left(j T_{e}\right)}\right)\right)
\end{aligned}
$$

The block diagram of the PMSM-control system is given in Fig. 9. Based on the Fig. 9 diagram and on the equations (3), (8), (9) and (10), we had found that the faulty phase detection can be realized by comparing the three phase to phase voltages. For an intermittent fault between the turns of the phase " $a$ ", $v_{b c}$ will be much less influenced by the presence of fault than $v_{a b}$ or $v_{c a}$. To clarify our statement we will develop in the follow the analytical expression of the deformation in each phase to phase voltage.

We suppose that the statoric currents can be written as the sum of healthy sinusoidal currents and deformations due to fault occurrence (equation (11))

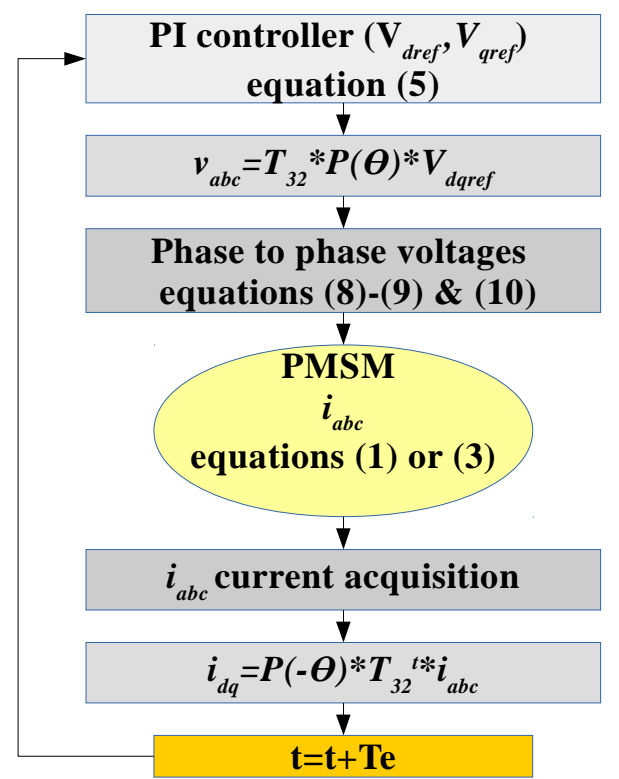

Fig. 9 : Block diagram of the PMSM-control system 


$$
\left\{\begin{array}{l}
i_{a}=i_{a \text { healthy }}+\text { dist }_{i a} \\
i_{b}=i_{b \text { healthy }}+\text { dist }_{i b} \\
i_{c}=i_{c \text { healthy }}+\text { dist }_{i c}
\end{array}\right.
$$

As the stator is star coupled, the sum of the current is null. Or during a healthy functioning, the sum of the stator current is null. Thereby, the sum of the currents deformations in the three phases is also null (equations (12), (13) and (14)).

$$
\begin{gathered}
i_{a}+i_{b}+i_{c}=0 \\
i_{\text {ahealthy }}+i_{\text {bhealthy }}+i_{\text {chealthy }}=0 \\
d i s t_{i a}+\text { dist }_{i b}+\text { dist }_{i c}=0
\end{gathered}
$$

We also suppose that the phase to phase voltages can be written as the sum of healthy sinusoidal voltages and deformations due to fault occurrence (equation (15)).

$$
\left\{\begin{array}{l}
v_{a b}=v_{a b \text { healthy }}+\text { dist }_{v a b} \\
v_{b c}=v_{b c \text { healthy }}+\text { dist }_{v b c} \\
v_{c a}=v_{\text {ca healthy }}+\text { dist }_{v c a}
\end{array}\right.
$$

We suppose that an intermittent inter-turn fault had occurred between the turns of the phase " $a$ " and generated a deformation in the current $i_{a}$ between the times $t_{n}$ and $t_{m}$ as shown in Fig. 10. The phase to phase voltages at $t_{n}$ are calculated based on the current collected at $t_{n-1}$. If we neglect the measurement noise, the calculated voltages can be considered as not disturbed by the presence of the intermittent fault. Only the statoric currents are disturbed. According to equation (3), the resulting $\left(i_{b}-i_{c}\right)_{n T_{e}}$ depends on zero fault parameter and is calculated based on $\left(v_{b}-v_{c}\right)_{n T_{e}}$. As $v_{b c n T_{e}}$ is healthy, the difference $\left(i_{b}-\right.$ $\left.i_{c}\right)_{n T_{e}}$ is independent from the fault occurrence. In other words, it is the same as in a healthy case and we can write equation (16).

$$
\text { dist }_{\text {ia } n T_{e}}=-0.5 \text { dist }_{i b n T_{e}}=-0.5 \text { dist }_{i c n T_{e}}
$$

At $t_{n+l}$, the phase to phase voltages depends on the currents collected at $t_{n}$, therefore they are disturbed by the fault presence. In equation (17), we present the distortions in $v_{a b(n+1) T_{e}}, v_{b c(n+1) T_{e}}$ and $v_{c a(n+1) T_{e}}$.

$$
\left\{\begin{array}{l}
\text { dist }_{v a b(n+1) T_{e}}=-\left(k_{p}+T_{e} k_{i}\right)\left(1.5 \text { dist }_{i a n T_{e}}\right) \\
\text { dist }_{v b c(n+1) T_{e}}=0 \\
\text { dist }_{v c a(n+1) T_{e}}=\left(k_{p}+T_{e} k_{i}\right)\left(1.5 \text { dist }_{i a n T_{e}}\right)
\end{array}\right.
$$

A $\operatorname{dist}_{v b c(n+1) T_{e}}$ null means that the difference $\left(i_{b}-i_{c}\right)_{(n+1) T_{e}}$ is independent from the fault occurrence at $t_{n}$. It leads to the equation (18).

$\operatorname{dist}_{i a(n+1) T_{e}}=-0.5$ dist $_{i b(n+1) T_{e}}=-0.5$ dist $_{i c(n+1) T_{e}}($

In the following and in order to simplify the calculus of the voltages distortion (dist $\left.t_{v a b}, d i s t_{v b c}, d i s t_{v c a}\right)$, we suppose that:

$$
\begin{aligned}
& \forall t \in\left[t_{n}, t_{m}\right], \\
& \quad \operatorname{dist}_{i a(t)}=-0.5 \operatorname{dist}_{i b(t)}=-0.5 \operatorname{dist}_{i c(t)}
\end{aligned}
$$

For a current collected at a time $t_{k} \in\left[t_{n}, t_{m}\right]$, and using the hypothesis in equation (19), we give the voltages distortions in equation (20). The analytical expressions of (dist $t_{v a b}$, dist $\left._{v b c}, d i s t_{v c a}\right)$ show that the comparison in the different distortion modulus should be done by comparing dist $_{v b c(k+2) T_{e}}$ (and not dist $t_{v b c(k+1) T_{e}}$ ) to $\operatorname{dist}_{v a b(k+1) T_{e}}$ and dist $_{v c a}(k+1) T_{e}$.

$$
\left\{\begin{array}{c}
\operatorname{dist}_{v a b(k+1) T_{e}}=-1.5 k_{p} \text { dist }_{i a k T_{e}} \\
-k_{i} T_{e} \sqrt{3} \sum_{j=n}^{k}\left(\sin \left[(k-j) \Delta \theta+\frac{2 \pi}{3}\right] \operatorname{dist}_{i a j T_{e}}\right) \\
\operatorname{dist}_{v b c(k+2) T_{e}}=-k_{i} T_{e} \sqrt{3} \sum_{j=n}^{k}\left(\sin [(k-j+1) \Delta \theta] \operatorname{dist}_{i a j T_{e}}\right) \\
\operatorname{dist}_{v c a(k+1) T_{e}}=1.5 k_{p} \text { dist }_{i a k T_{e}} \\
-k_{i} T_{e} \sqrt{3} \sum_{j=n}^{k}\left(\sin \left[(k-j) \Delta \theta-\frac{2 \pi}{3}\right] \operatorname{dist}_{i a j T_{e}}\right)
\end{array}\right.
$$

With

$$
\Delta \theta=\theta_{(j+1) T_{e}}-\theta_{j T_{e}}
$$

The comparison between the distortions in equation (20) depends on the values of $\operatorname{dist}_{i a(j) T_{e}}$ with $j \in[n, k]$. The shape of this distortion is given in Fig. 10. As we can see, in absence of intermittent short circuit, there is only measurement noise. When an intermittent fault occurs, it generates the deformation marked between $t_{n}$ and $t_{m}$.

Our fault localization method is based on the amplitude comparison of the phase to phase voltages distortions. Its purpose is to identify the faulty phase through a difference in the peaks amplitudes in these voltages. Using the equation (20), we had found that only the part of the dist $t_{i a}$ included between the times $t_{n}$ and $t_{M D}$ is needed to calculate the peaks in the phase to phase voltages distortions. $t_{M D}$ is the time corresponding to the maximum deformation value in $i_{a}$ current. Based on this, and in order to simplify the comparison in the different distortion modulus in this paper, we will place in the time interval $\left[t_{n}, t_{M D}\right]$. In this interval, $\mid$ dist $_{a} \mid$ is an increasing function. Therefore,

$$
\forall t_{j} \in\left[t_{n}, t_{M D}\left[,\left|\operatorname{dist}_{i a t_{j}}\right|<\mid \text { dist }_{\text {ia }_{j+1}} \mid\right.\right.
$$

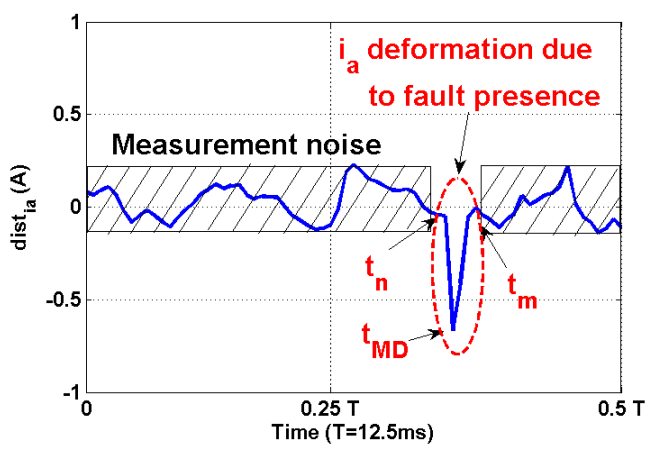

Fig. 10 : Shape of the distortion in the current $i_{a}$ 
A detailed study using the equations (20) to (22) had led us to conclude that the peaks in the distortion $d_{i s t_{v b c}}$ are smaller than those in $d i s t_{v a b}$ and $d i s t_{v c a}$. The simulation and experimental tests presented subsequently confirmed our statements. Due to space limitation in this paper, we will consider some hypothesis based on the usual PMSM control conditions. They simplify the explanation of the faulty phase detection method and they allow us to give an amplitude order for the different distortions in the phase to phase voltages. The considered hypothesis are:

1. The sampling frequency $\left(f_{e}=\frac{1}{T_{e}}\right)$ is much higher than the electrical frequency $\left(f=\frac{1}{2 \pi} \frac{d \theta}{d t}=\frac{\omega}{2 \pi}, \omega\right.$ being the electrical speed).

$$
f_{e} \geq 10 f \Rightarrow \Delta \theta=\omega T_{e} \leq \frac{\pi}{5}
$$

2. The PI current controller gains are calculated according to equation (24) with $\tau$ the machine electrical time constant $\left(\frac{L_{S}}{R_{S}}\right)^{-1}$.

$$
k_{i}=k_{p} \tau
$$

3. The steady state mode is reached after $3 \tau$ with a minimum of $10 T_{e}$ (equation (25)).

$$
T_{e} k_{i}=T_{e} k_{p}\left(\frac{L_{S}}{R_{S}}\right)^{-1} \leq \frac{3}{10} k_{p}
$$

4. The stator imbalance generates a deviation in the current against its reference until the current controller responds and corrects it. Only this distortion is taken into account. The measurement noise is neglected.

5. In accordance with point (3), and as the studied fault is an incipient intermittent short circuit, we suppose that the time interval $\left[t_{n}, t_{M D}\right]$ cannot exceed an electrical period quarter.

$$
t_{M D}-t_{n} \leq \frac{T}{4} \text { with } T=\frac{1}{f}=\frac{2 \pi}{\omega}
$$

To give a distortion amplitude order, we will place in the limit case given in equation (27). If $d i s t_{v b c}$ peaks are smaller than dist $_{v a b}$ and dist $_{v c a}$ peaks in this limit case, they will be in the rest of the cases satisfying the 5 hypothesis.

$$
\left\{\begin{array}{c}
f_{e}=10 f \\
\Delta \theta=\omega T_{e}=\frac{\pi}{5} \\
T_{e} k_{i}=\frac{3}{10} k_{p} \\
t_{M D}-t_{n} \leq 2.5 T_{e}
\end{array}\right.
$$

In table 2, we present the three voltages distortions calculated using equations (20) and (27) for a current collected at a time $t_{k} \in\left[t_{n}, t_{M D}\right](k=n, n+1, n+2, n+3)$.

$$
\text { With } D_{k}=k_{p} \operatorname{dist}_{\text {ia } k T_{e}} ;(k=n, n+1, n+2, n+3)
$$

Based on Fig. 10, for $t_{k} \in\left[t_{n}, t_{M D}\right], D_{k}$ is negative with $\left|D_{k}\right|<\left|D_{k+1}\right|$. Thus for $k=n, n+1, n+2, n+3$,

$$
\left|\operatorname{dist}_{v b c(k+2) T_{e}}\right|<\mid \text { dist }_{v a b(k+1) T_{e}}|<| \text { dist }_{v c a(k+1) T_{e}} \mid
$$

Based on the conclusion in equation (29), we had found that $\left|d i s t_{v b c}\right|$ is always lesser than $\left|d i s t_{v a b}\right|$ and $\left|d i s t_{v c a}\right|$. This result means that a comparison between the three phase to phase voltages can identify the faulty phase.

In Fig. 11 is presented an example of $v_{a b}, v_{b c}$ and $v_{c a}$. It was obtained by the PMSM Matlab simulation under fault conditions on the phase " $a$ ". The presented operating point correspond to the following setting: $I_{\text {qref }}=2 \mathrm{~A}, \Omega=600 \mathrm{rpm}$, $k_{p}=15, \mu=6.25 \%$ and $R_{f . s c . o n}=0$. As we can see, $v_{b c}$ (in green) is quasi not disturbed at the moment when the interturn fault occurs or disappears compared to $v_{a b}$ (in blue) and $v_{c a}$ (in red).

\section{2) Online phase identification method}

Based on the analysis presented previously, we have developed an online phase identification method. The idea is to filter the fundamental frequency from $v_{a b}, v_{b c}$ and $v_{c a}$ using a high pass filter. In case of intermittent fault occurrence on the phase " $x$ " of a " $x y z$ " stator, $v_{y z}$ supplying the two other phases will be less disturbed than $v_{x y}$ and $v_{z x}$. " $x$ " can be eventually the phase " $a$ ", " $b$ " or " $c$ ".

Table 2: The three phase to phase voltages distortions

\begin{tabular}{|l|l|l|c|}
\hline $\boldsymbol{k}$ & $\boldsymbol{d i s t}_{\boldsymbol{v a b}(\boldsymbol{k}+\mathbf{1}) \boldsymbol{T}_{\boldsymbol{e}}}$ & $\boldsymbol{d i s t}_{\boldsymbol{v b c}(\boldsymbol{k}+\mathbf{2}) \boldsymbol{T}_{\boldsymbol{e}}}$ & $\boldsymbol{d i s t}_{\boldsymbol{v c a}(\boldsymbol{k}+\mathbf{1}) \boldsymbol{T}_{\boldsymbol{e}}}$ \\
\hline $\boldsymbol{n}$ & $-1.95 D_{n}$ & $-0.30 D_{n}$ & $+1.95 D_{n}$ \\
\hline $\boldsymbol{n}+\mathbf{1}$ & $-1.95 D_{(n+1)}$ & $-0.30 D_{(n+1)}$ & $+1.95 D_{(n+1)}$ \\
& $-0.21 D_{n}$ & $-0.49 D_{n}$ & $+0.52 D_{n}$ \\
\hline \multirow{4}{*}{$\boldsymbol{n + 2}$} & $-1.95 D_{(n+2)}$ & $-0.30 D_{(n+2)}$ & $+1.95 D_{(n+2)}$ \\
& $-0.21 D_{(n+1)}$ & $-0.49 D_{(n+1)}$ & $+0.52 D_{(n+1)}$ \\
& $+0.11 D_{n}$ & $-0.49 D_{n}$ & $+0.39 D_{n}$ \\
\hline \multirow{4}{*}{$\boldsymbol{n + 3}$} & $-1.95 D_{(n+3)}$ & $-0.30 D_{(n+3)}$ & $+1.95 D_{(n+3)}$ \\
& $-0.21 D_{(n+2)}$ & $-0.49 D_{(n+2)}$ & $+0.52 D_{(n+2)}$ \\
& $+0.11 D_{(n+1)}$ & $-0.49 D_{(n+1)}$ & $+0.39 D_{(n+1)}$ \\
& $+0.39 D_{n}$ & $-0.30 D_{n}$ & $+0.11 D_{n}$ \\
\hline
\end{tabular}

In Fig. 12, we present an example of the online localization method. The Figure contains the filtered $v_{a b}, v_{b c}$ and $v_{c a}$ for a period of $3 \mathrm{~s}$ in order to include a maximum number of intermittent fault occurrence. It was obtained for the same simulation case presented in Fig. 11. As we can see, the two filtered phase to phase voltages $v_{a b}$ (in blue) and $v_{c a}$ (in red) contain peaks corresponding to the intermittent fault presence on the phase " $a$ " whereas, the filtered $v_{b c}$ (in green) is quasi not disturbed.

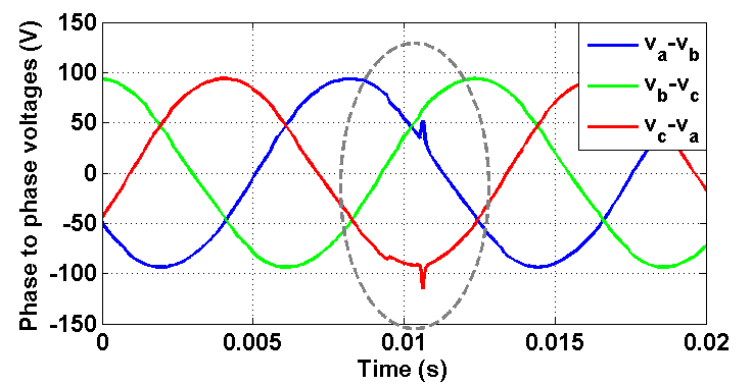

Fig. 11 : Simulation phases to phase voltages with an intermittent fault on the phase " $a$ " 


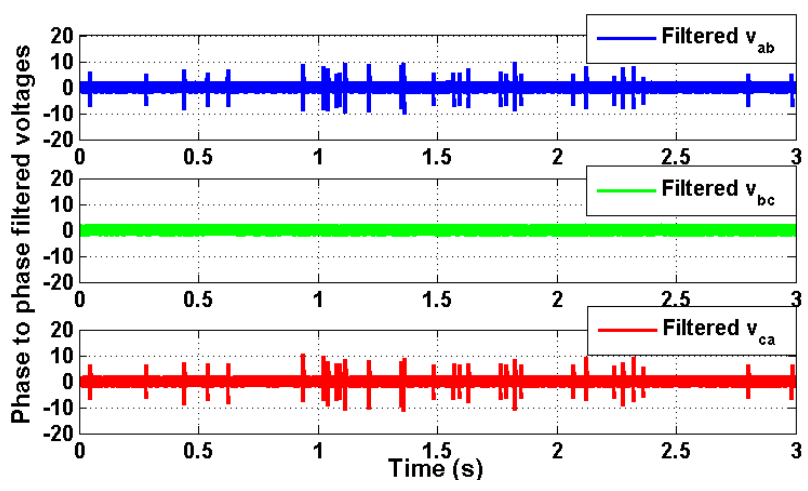

Fig. 12 : Simulation filtered phase to phase voltages with an intermittent fault on the phase " $a$ "

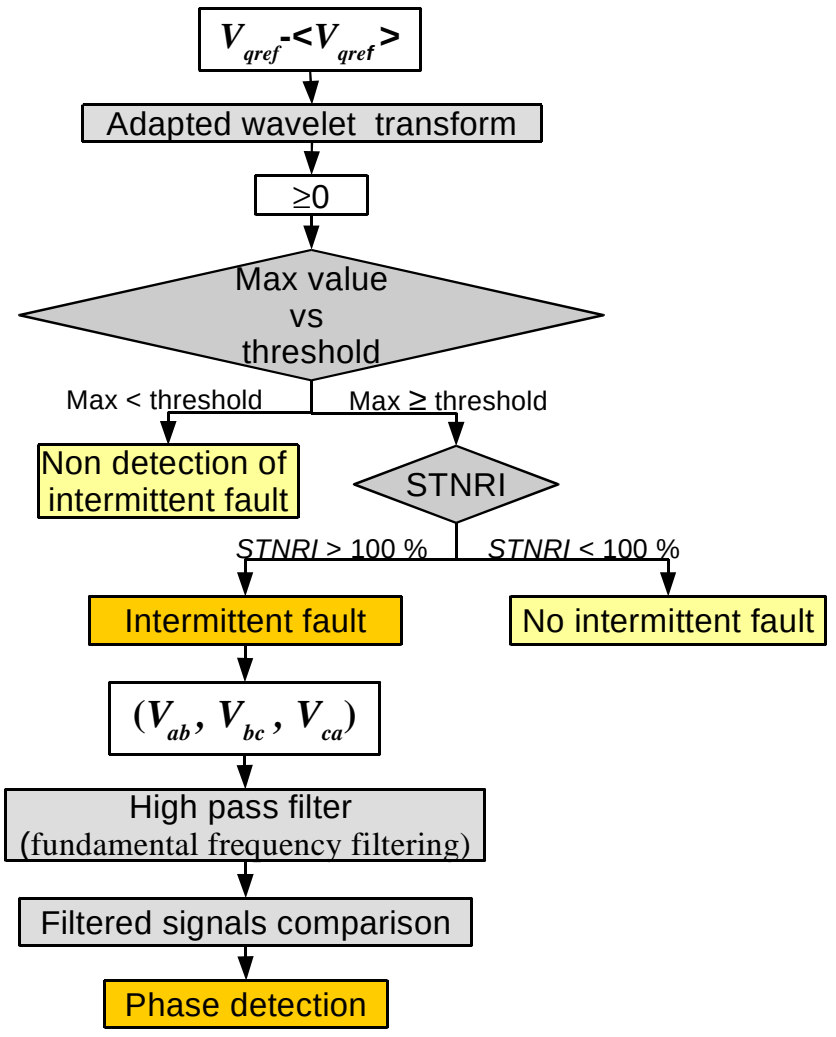

Fig. 13 : Intermittent inter-turn fault detection and localization

\section{Resume of the detection method}

A summary of the whole detection method is given in Fig. 13. Starting from the intermittent fault detection and arriving to the localization of the phase containing the defected turns.

\section{EXPERIMENTAL RESULTS}

Theoretical and experimental tests were realized to validate the intermittent fault identification and localization method. The intermittent inter-turn fault was realized using a controllable switch. Both simulations and theoretical tests had succeeded. Because of space limitation in the paper, only experimental results will be exposed in this section. Different operating cases were treated by varying the control or/and the intermittent fault parameters. We have chosen to present four of them with an intermittent fault on the phase " $a$ ".
Case 1: $I_{\text {qref }}=2 \mathrm{~A}, \Omega=600 \mathrm{rpm}, k_{p}=15, \mu=6.25 \%$ and $R_{\text {f.scon }}=0 \mathrm{Ohms}$

$>$ Case 2: $I_{\text {qref }}=2 \mathrm{~A}, \Omega=600 \mathrm{rpm}, k_{p}=15, \mu=50 \%$ and $R_{\text {f.scon }}=7.5 \mathrm{Ohms}$

$>$ Case 3: $I_{\text {qref }}=5 \mathrm{~A}, \Omega=1050 \mathrm{rpm}, k_{p}=20, \mu=6.25 \%$ and $R_{f . s c . o n}=0 \mathrm{Ohms}$

$>$ Case 4: $I_{\text {qref }}=5 \mathrm{~A}, \Omega=1050 \mathrm{rpm}, k_{p}=25, \mu=50 \%$ and $R_{f . s c . o n}=7.5 \mathrm{Ohms}$

The results presentation will be divided into two parts: the first is the intermittent inter-turn fault detection and the second is the phase localization.

\section{A. Intermittent fault detection results}

For all the tested cases, the intermittent inter-turn detection method had succeeded. In table 2, we present the STNRI values obtained for the four experimental cases. The obtained values varies between $124 \%$ and $199 \%$. As they are higher than $100 \%$, it means that the fault signature identification has occurred and that the wavelet transform has improved the signal to noise ratio. The intermittent fault identification stage has succeeded, so we proceed to the localization of the faulty phase.

\section{B. Phase localization results}

The localization method developed in section III has succeeded in the localization of the faulty phase for all the studied cases. In the follow, we will present the results of the four experimental cases. In Fig. 14, we begin with a zoom on the experimental $v_{a b}, v_{b c}$ and $v_{c a}$ in case 1 . As we can see, $v_{b c}$ (in green) is quasi not disturbed by the intermittent fault while $v_{a b}$ (in blue) and $v_{c a}$ (in red) present deformations due to fault presence.

In Fig. 15 to 18, we present the filtered $v_{a b}, v_{b c}$ and $v_{c a}$ for the cases 1 to 4 . As we can notice, for all the cases, the filtered $v_{b c}$ (in green) is not disturbed by the fault presence compared to $v_{a b}$ (in blue) and $v_{c a}$ (in red). Thus, this detection method has succeed to detect the faulty phase.

Table 3 : STNRI experimental values

\begin{tabular}{|c|c|}
\hline Case & STNRI \\
\hline 1 & $147 \%$ \\
\hline 2 & $141 \%$ \\
\hline 3 & $124 \%$ \\
\hline 4 & $199 \%$ \\
\hline
\end{tabular}

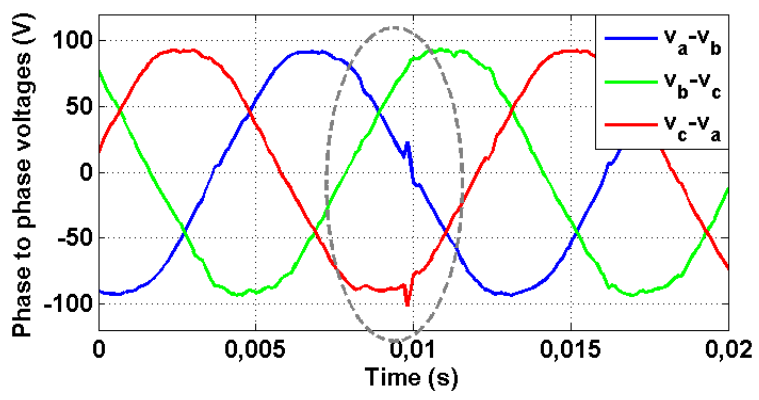

Fig. 14 : Experimental phases to phase voltages with an intermittent fault on the phase " $a$ ", case 1 


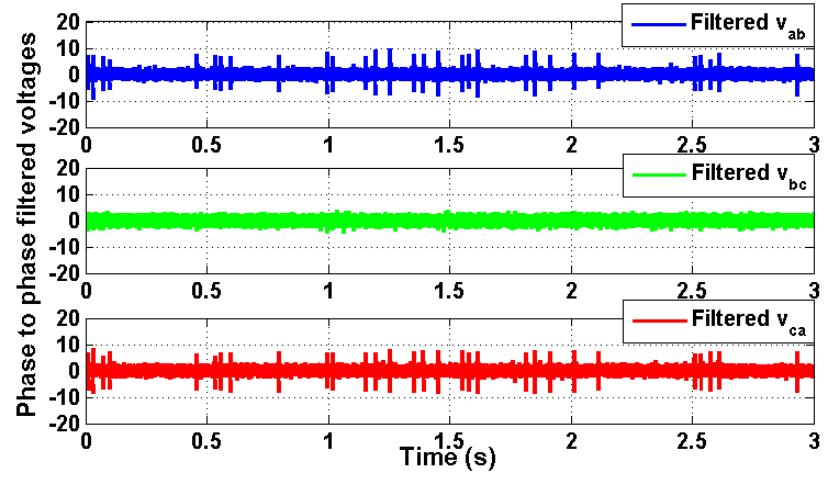

Fig. 15 : Experimental filtered phase to phase voltages with an intermittent fault on the phase " $a$ ", case 1

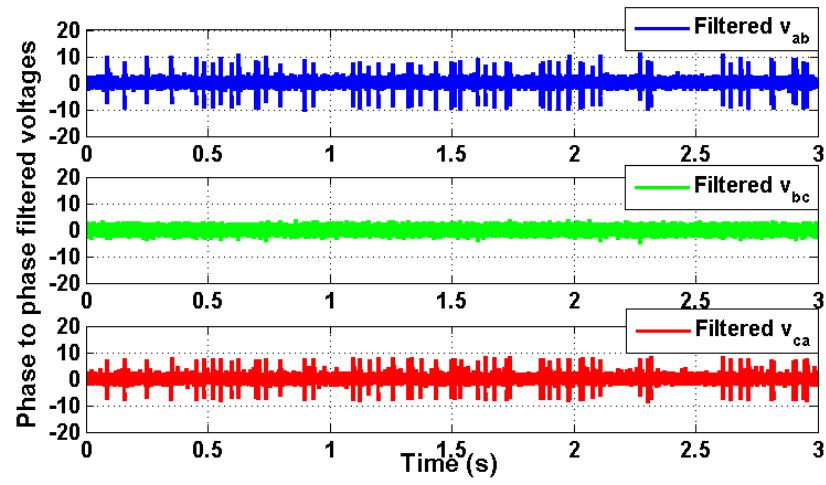

Fig. 16 : Experimental filtered phase to phase voltages with an intermittent fault on the phase " $a$ ", case 2

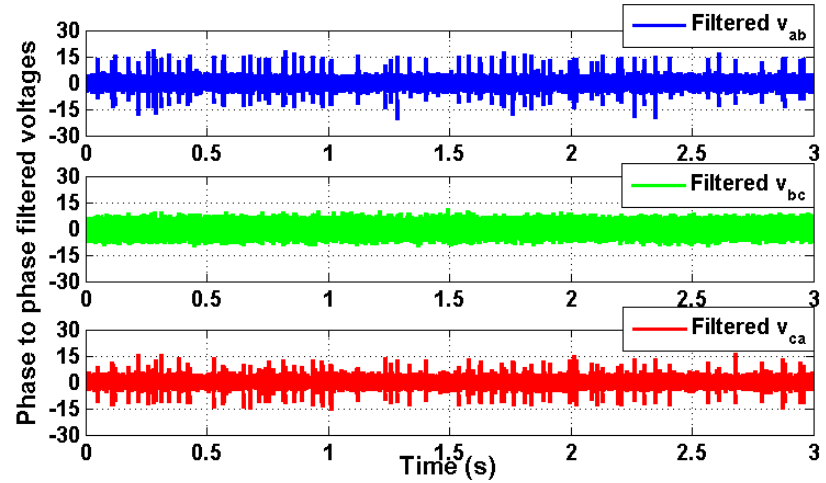

Fig. 17 : Experimental filtered phase to phase voltages with an intermittent fault on the phase " $a$ ", case 3

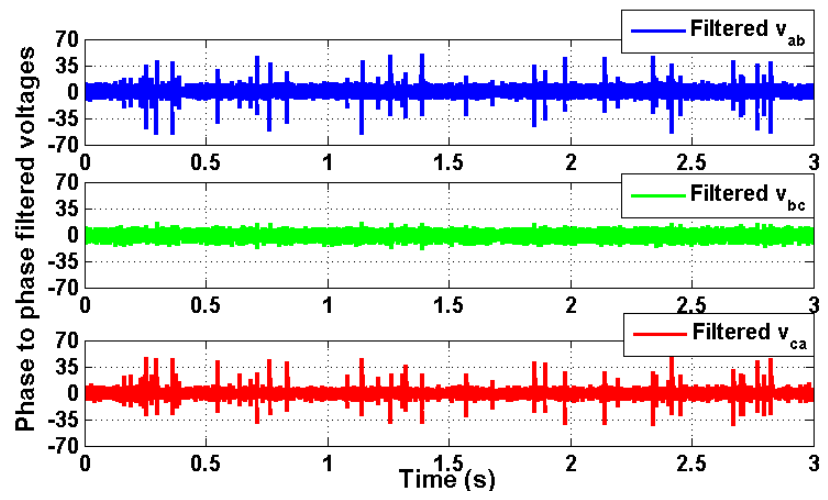

Fig. 18 : Experimental filtered phase to phase voltages with an intermittent fault on the phase " $a$ ", case 4

\section{CONCLUSION}

In the automotive field, the maintenance strategies play an important role. In this paper, we are interested in studying detection method that could be implemented to onboard diagnostics (OBD). We have examine incipient stator fault and we have presented a fault detection and localization method. The developed study can be used in a preventive/corrective maintenance strategy.

Incipient fault appears as intermittent inter-turn short circuit between two slightly damaged turns. Their presence introduces specific distortions to the statoric currents as well as the reference voltages. These distortions are considered as the intermittent inter-turn fault signatures and their patterns are used for fault detection. The identification procedure is based on an adapted wavelet transform. Its basis was built using the fault signature. The transform is applied to the reference voltage $V_{\text {qref }}$ after removing its means value. Once the intermittent fault detected, its localization method consists in comparing the phase to phase voltages. For a "xyz" stator with an intermittent fault on the phase " $x$ ", the phase to phase voltage $v_{y z}$ supplying the two other phases will be less disturbed than $v_{x y}$ and $v_{z x}$. " $x$ " can be eventually the phase " $a$ ", " $b$ " or " $c$ ".

The developed method is an online one. It presents the advantages to identify the intermittent fault, to discriminate it from other types, to improve the signal to noise ratio and to locate the faulty phase. However, it has limits. The two major limits leading to the none detection of the intermittent fault are a very small number of turns involved in the fault $(\mu)$ and a very high short circuit resistance $\left(R_{f . s c o n}\right)$. Theoretical and experimental tests have proven the effectiveness of this method not only in identifying and localizing the intermittent fault but also in improving the signal to noise ratio. This result was particularly useful when the fault signature was relatively small.

\section{REFERENCES}

[1] ISO 26262, "Road vehicles - Functional safety", International Organization for Standardization, 2011.

[2] J. Zhang, H. Yao, G. Rizzoni, "Fault Diagnosis for Electric Drive Systems of Electrified Vehicles Based on Structural Analysis," IEEE Trans on Vehicular Tech., Vol. 66, No. 2, pp. 1027-1039, Feb 2017.

[3] G. Feng, C. Lai, K. Mukherjee, N. C. Kar, "Current InjectionBased Online Parameter and VSI Nonlinearity Estimation for PMSM Drives Using Current and Voltage DC Components," IEEE Trans. on transp. electrification, Vol.2, no.2, pp.119-128 June 2016. [4] C. Lu, S. Ferrari, G. Pellegrino, "Two Design Procedures for PM Synchronous Machines for Electric Powertrains," IEEE Trans. on transp. electrification, Vol. 3, No. 1, pp. 98-107, March 2017.

[5] J. Penman, H.G. Sedding, Al Lloyd, W.T Fink, "Detection and localization of inter turn short circuits in the stator windings of operation motors," IEEE Trans. Energy Conv., Vol. 9, No. 4, pp. 652-658, Dec. 1994.

[6] S. Grubic, J. Aller, B. Lu, and T. Habetler, "A survey on testing and monitoring methods for stator insulation systems of low-voltage induction machines focusing on turn insulation problems," IEEE Trans. Ind. Electron., vol. 55, no. 12, pp. 4127-4136, Dec. 2008. 
[7]B. Du, S. Wu, S. Han, and S. Cui, "Interturn fault diagnosis strategy for interior permanent-magnet synchronous motor of electric vehicles based on digital signal processor", IEEE Trans. Ind. Electron., vol. 63, no. 3, march 2016.

[8] S. Cheng, T. G. Habetler, "Using Only the DC Current Information to Detect Stator Turn Faults in Automotive Claw-Pole Generators", IEEE Trans. Ind. Electron., vol. 60, no. 8, Aug. 2013.

[9] B. Aubert, J. Regnier, S. Caux, and D. Alejo, "Kalman-filterbased indicator for online interturn short circuits detection in permanent-magnet synchronous generators," IEEE Trans. Ind. Electron., vol. 62, no. 3, pp. 1921-1930, Mar. 2015.

[10] F. Çira, M. Arkan and B. Gümüş, "A new approach to detect stator fault in permanent magnet synchronous motors," in Proc. IEEE 10th Int. Symp. Diag. Elect. Mach., Power Electronics and Drives, Sept. 2015, pp. 316-321.

[11] N. Leboeuf, T. Boileau, B. Nahid-Mobarakeh, G. Clerc, and F. Meibody- Tabar, "Real-time detection of interturn faults in $\mathrm{pm}$ drives using backemf estimation and residual analysis," IEEE Trans. Ind. Appl., vol. 47, no. 6, pp. 2402-2412, Dec. 2011.

[12] T. Boileau, N. Leboeuf, B. Nahid-Mobarakeh, and F. MeibodyTabar, "Synchronous demodulation of control voltages for stator interturn fault detection in PMSM," IEEE Trans. Power Electron., vol. 28, no. 12, pp. 5647-5654, Dec. 2013.

[13] N. Haje Obeid, T. Boileau and B. Nahid-Mobarakeh, "Modeling and diagnostic of incipient inter-turn faults for a three phase permanent magnet synchronous motor," IEEE Trans. Ind. Appl., vol. 52, no. 5, pp. 4426-4434, Sept.-Oct. 2016.

[14] K.C. Kim, H.W. Lee, Y. D. Chun, and J. Lee, "Analysis of electromagnetic force distribution on end winding for motor reliance,"IEEE Trans.Magn.,vol.41, no.10,pp.4072-4074, Oct.2005. [15] R. Lin, A. N. Laiho, A. Haavisto, and A. Arkkio, "End-winding vibrations caused by steady-state magnetic forces in an induction machine," IEEE Trans.Magn.,vol.46, no.7, pp.2665-2674, Jul.2010. [16] M. R. Bissonnette, "End-winding vibrationmonitoring and interpretation," in Proc. IEEE Conf. Rec. Int. Symp. Elect. Insul., Jun. 2012, pp. 285-290.

[17] N. Haje Obeid, T. Boileau, B. Nahid-Mobarakeh, "Modèle dynamique et signature du défaut inter-spire intermittent dans les têtes de bobines d'une MSAP," Symposium de Génie Electrique, Grenoble, France, Juin 2016.

[18] B. Vaseghi, N. Takorabet, and F. Meibody-Tabar, "Fault analysis and parameter identification of permanent-magnet motors by the finiteelement method," IEEE Trans. Magn., vol. 45, no. 9, pp. 3290-3295, Sep. 2009.

[19] S. Das, P. Purkait, D. Dey, and S. Chakravorti, "Monitoring of interturn insulation failure in induction motor using advanced signal and data processing tools," IEEE Trans. Dielect. Elect. Insul., vol. 18, no. 5, pp. 1599- 1608, Oct. 2011.

[20] Z. Chen, R. Qi, and H. Lin, "Inter-turn short circuit fault diagnosis for PMSM based on complex gauss wavelet," in Proc. IEEE Int. Conf. Wavelet Anal. Pattern Recog., Nov. 2007, vol. 4, pp. 1915-1920.

[21] M. Misiti, Y. Misiti, G. Oppenheim, and J. M. Poggi, Wavelets and Their Applications. Hoboken, NJ, USA: Wiley, 2013.

[22] T. G. Nair, A. Geetha, and M. Asharani, "Adaptive wavelet based identification and extraction of PQRST combination in randomly stretching ECG sequence," in Proc. IEEE China Summit Int. Conf. Signal Inf. Process., Jul.2013, pp. 278-282.

[23] A. Aldroubi, P. Abry, and M. Unser, "Construction of biorthogonal wavelets starting from any two multi-resolutions," IEEE Trans. Signal Process., vol.46, no.4, pp.1130-1133, Apr.1998. [24] J. O. Chapa and R. M. Rao, "Algorithms for designing wavelets to match a specified signal," IEEE Trans. Signal Process., vol. 48, no. 12, pp. 3395-3406, Dec. 2000.

[25] A. Gupta, S. D. Joshi, and S. Prasad, "A new approach for estimation of statistically matched wavelet," IEEE Trans. Signal Process., vol. 53, no. 5, pp. 1778-1793, May2005.
[26] J. Rafiee, P. Tse, A. Harifi, and M. Sadeghi, "A novel technique for selecting mother wavelet function using an intelligent fault diagnosis system," Expert Syst. Appl., vol. 36, no. 3, pp. 48624875, 2009.

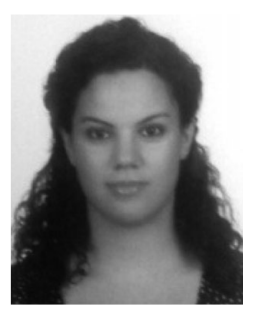

Najla Haje Obeid received the Ph.D. degree in electrical engineering from the university of Lorraine, Nancy, France in 2016. She joined the IFP Energies Nouvelles, Rueil-Malmaison, France, in November 2016, where she is currently working at the mechatronic and numeric department. Her main research interests include fault detection, modeling, and control of electric machines.

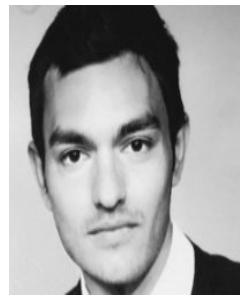

Alexandre Battiston received the Ph.D. degree in electrical engineering from the university of Lorraine, Nancy, France in 2014. He joined the IFP Energies Nouvelles, Rueil-Malmaison, France, in October 2014, where he is currently a research engineer in power electronics at the mechatronic and numeric department. His research interests include power electronics architectures \& controls and their applications.

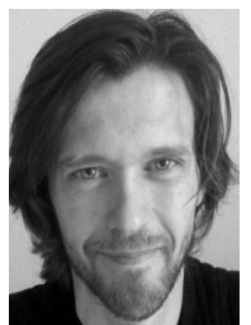

Thierry Boileau received the Ph.D. degrees in electrical engineering from the Institut National Polytechnique de Lorraine, Nancy, France, in 2010. In September 2012, he joined the École Nationale Supérieure d'Électricité et de Mécanique, at the University of Lorraine, Nancy, where he is currently an Associate Professor and where he is also with the Groupe de Recherche en Électrotechnique et Électronique de Nancy. His main research interests include diagnostics and control of electrical machines supplied by static converters.

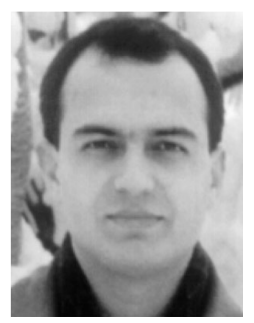

Babak Nahid-Mobarakeh (SM'12) received the $\mathrm{Ph} . \mathrm{D}$. degree in electrical engineering from the Institut National Polytechnique de Lorraine, Nancy, France, in 2001. From 2001 to 2006, he was at the Centre de Robotique, Électrotechnique et Automatique, University of Picardie, Amiens, France. In September 2006, he joined Ecole Nationale Supérieure d'Électricité et de Mécanique, University of Lorraine, Nancy, where he is currently an Associate Professor, and where he is also with the Groupe de Recherche en Électrotechnique et Électronique de Nancy. He is the author of more than 150 international papers. His main research interests include nonlinear and robust control techniques, fault detection, and stabilization. 